\title{
Neurological deficit in a consecutive series of vertebral fracture patients with bony fragments within spinal canal
}

\author{
N Rosenberg ${ }^{1}$, R Lenger ${ }^{2}$, I Weisz ${ }^{1}$ and H Stein ${ }^{1}$ \\ ${ }^{1}$ Department of Orthopedic Surgery 'A', Rambam Med. Center, Haifa, Israel; ' Department of Rehabilitation 'H', \\ Fleeman Hospital, Haifa, Israel
}

\begin{abstract}
The wide spread availability of computerized tomography has added a new dimension to the anatomical evaluation of vertebral fractures. This diagnostic modality has shown that in these fractures, the protrusion of bone spicules into the spinal canal is often encountered. The clinical significance of this finding and its relation to the need of establishing indications for surgery in these patients is controversial.

The neurological outcome of patients with postraumatic bony encroachment of the spinal canal is not well documented in the literature, and therefore the adequate therapeutic approach is neither clear nor is it unanimous. Whether treatment should be aggressively surgical with decompression and/or segmental fusion, or conservative, the goal has to be prevention of secondary injury to the spinal cord.

This presentation is a mean 4 year follow up study of 38 consecutive patients with spinal fractures and spinal canal narrowing, who were treated conservatively. The results demonstrate that the initial neurological findings have a very significant prognostic value for the neurological outcome, regardless of the spinal segment involved, the type of injury and spinal canal narrowing as demonstrated by computerized tomograms.

We conclude that in trauma patients with vertebral fractures and spicules in the spinal canal without evidence of an initial neurological deficit, a favorable neurological prognosis can be predicted, following conservative management.
\end{abstract}

Keywords: vertebral fractures; vertebral canal bony fragments; spinal canal narrowing; neurological deficit; computerized tomography

\section{Introduction}

The development of permanent neurological damage is both the most serious and most debilitating complication of spinal fractures. Its pathogenesis has been attributed to intraneural hemorrhages followed by irreversible damage to the gray matter of the spinal cord. $^{1,2}$ Hence, various therapeutic approaches have been recommended and practiced. Reports on the development or regression of neurological deficit in spinal fracture patients over a period of years are few $^{3-11}$ although this may further increase the understanding of this condition.

Radiological evidence of spinal canal narrowing following vertebral fractures has become a common finding since computerized tomography has developed into a widely available clinical imaging modality. This leaves open the question whether or to what extent this finding correlates with the development of neurological deficits. ${ }^{12-20}$ The answer to this question may contribute towards establishing a therapeutic

Correspondence: Dr Nahum Rosenberg, M.D. approach based upon findings of post traumatic spinal canal narrowing, an issue which still is controversial. $9,11,21-23$

The following is a report, which compares the extent of neurological deficit in a consecutive group of vertebral fracture patients, with $\mathrm{CT}$ evidence of bone fragments within spinal canal, immediately after injury and after a mean follow up period of 4 years (range $1-6$ years).

\section{Patients and methods}

Between 1st June 1982 to 1st June 1988, 63 consecutive patients with vertebral fractures, with radiographic evidence of bone fragments in the spinal canal and with no progressive neurological deterioration after admission, were treated. Their admission files and radiographic examinations were reviewed. In 1988 they were asked to attend a specialized follow-up clinic, where the examination protocol called for:

1 A detailed anamnesis.

2 A detailed clinical and neurological examination, using Frankel's criteria for objective assessment. ${ }^{24}$ 
3 A review of the initial postraumatic axial computerized tomograms of the fracture area extending one level above and one below the affected vertebrae, thus allowing assessment and localization of the extent of bone damage and of spinal alignment. Spinal canal narrowing was calculated as a percentage of the spinal canal diameter occupied by bony spicules compared to adjacent vertebral segments without spinal canal compromise.

Of the 63 patients, four had died (three of unrelated causes), 11 patients could not be traced and 10 did not attend the follow up clinic. Therefore the present study group consisted of 38 patients $(60 \%$ of the original group). Only in 23 of the patients the admission CT radiographs were available for reevaluation $36 \%$ of the patients included to this study group). Thirty-one of them $(82 \%)$ were males and seven $(18 \%)$ females. The mean age was 31 years (median 28 years, range 18-61 years). All of these patients did not show immediate progression of neurological deficit nor were they thought to have mechanical instability of the spine.

Therefore they were treated by conservative means. Patients with severe neurological deficit (tetraplegia or paraplegia) were transferred for rehabilitation to a Spinal Cord Rehabilitation Unit within 48-72 h. Those with slight, minimal or no neurological deficit were ambulated within 5 to 7 days. Those with a cervical spine fracture had Halo jacket immobilization, and those with thoracic and lumbar fractures were treated in a thoracolumbar plaster of paris (POP) jacket, which was removed after 3 months. The Halo jacket was retained for 3 to 4 months.

\section{Results}

Twenty-one patients $(55 \%)$ had sustained a high energy injury (road accident, gun shot or explosion injuries), while $17(45 \%)$ had a low energy injury (industrial or recreational sport injuries). To assess the severity of neurological impairment, Frankel's criteria were used.

On admission 12 patients (32\% of the group) presented with severe motor and sensory loss, $20 \%$ (10 patients) had minimal motor impairment, while $42 \%$ (16 patients) had no neurological abnormality. At follow up only seven patients $(18 \%$ of the study group) still had severe motor and sensory loss, $40 \%$ (15 patients) showed minimal motor impairment and $42 \%$ (16 patients) still had no neurological abnormality (Table 1). Statistical analysis of these data showed a significant relationship between the neurological status on admission and at follow up $(P=0.00001$, Chi square test). Five patients improved and their neurological status was upgraded from A to D using Frankel's criteria. The time of neurological recovery and the spinal segment involved are presented in Table 2.

In all of the patients reviewed, protruding bone fragments were present in the neural canal. In those patients with available $\mathrm{CT}$ documentation the varying degree of encroachment on the anteroposterior diameter of the spinal canal caused by these fragments was measured and was related to the extent of neurological impairment by Frankel's

Table 1 Patient's neurological status on admission and at follow up (by Frankel's criteria)

\begin{tabular}{lccccc}
\hline On & \multicolumn{5}{c}{ At follow up } \\
admission & $A$ & $B$ & $C$ & $D$ & $E$ \\
\hline A & 7 & - & - & 5 & - \\
B & - & - & - & - & - \\
C & - & - & - & - & - \\
D & - & - & - & 10 & - \\
E & - & - & - & - & 16 \\
\hline
\end{tabular}

Table 2 Injured spinal segment and time to neurological improvement in five patients

\begin{tabular}{lcc}
\hline Patient no. & $\begin{array}{c}\text { Time to neurological } \\
\text { improvement (days) }\end{array}$ & $\begin{array}{c}\text { Spinal segment } \\
\text { injured }\end{array}$ \\
\hline 1 & 4 & $\mathrm{~T} 12$ \\
2 & 15 & $\mathrm{C} 4, \mathrm{C} 5$ \\
3 & 45 & $\mathrm{C} 6$ \\
4 & 30 & $\mathrm{C} 6, \mathrm{C} 7$ \\
5 & 75 & $\mathrm{C} 5, \mathrm{C} 6, \mathrm{C} 7$ \\
\hline
\end{tabular}

Table 3 Neurological status and degree of spinal canal narrowing in patients with involvement of different spinal segments

\begin{tabular}{lcc}
\hline $\begin{array}{l}\text { Spinal segment } \\
\text { involved }\end{array}$ & $\begin{array}{c}\text { Spinal canal } \\
\text { narrowing }(\%)\end{array}$ & $\begin{array}{c}\text { Neurological status } \\
\text { (Frankel) }\end{array}$ \\
\hline C1 & 10 & E \\
C2 & 10 & E \\
C2 & 10 & D \\
C4 & 27 & A \\
C4 & 10 & E \\
C4 & 63 & A \\
C5 & 43 & A \\
C5 & 70 & E \\
C6 & 33 & A \\
C6 & 20 & D \\
C7 & 20 & E \\
T12 & 45 & D \\
T12 & 40 & A \\
T12 & 33 & D \\
T12 & 50 & E \\
L1 & 10 & A \\
L1 & 70 & D \\
L1 & 70 & E \\
L2 & 67 & E \\
L2 & 70 & D \\
L2 & 75 & \\
L4 & 50 & \\
L5 & 10 & \\
\hline
\end{tabular}


criteria - Table 3. In this group of patients no statistically significant relationship could be demonstrated between the loss of neurological function on admission and the spinal canal narrowing $(P=0.26$, Analysis of variance). There was almost no difference between spinal canal narrowing above and below $50 \%$ for every neurological grade (Table 4). Regarding all of the patients evaluated, $68 \%$ (26 patients) had a favorable immediate neurological status (D and $\mathrm{E}$ by Frankel).

There was no significant relationship between the neurological deficit and the fractured spinal segment $(P=0.57$, Chi square test, Table 5). Neither high nor low energy injuries were related to the initial neurological status $(P=0.93$, Chi square test, Table 6).

\section{Discussion}

Although in all patients of this study group bone spicules were present in the spinal canal on admission, only $32 \%$ had a motor and sensory deficit of a degree

Table 4 Neurological status (Frankel) related to spinal canal narrowing of above and below $50 \%$

\begin{tabular}{|c|c|c|}
\hline \multirow[b]{2}{*}{ Neurological status } & \multicolumn{2}{|c|}{ Spinal canal narrowing } \\
\hline & Below $50 \%$ & Above $50 \%$ \\
\hline A & 4 & 3 \\
\hline $\mathrm{D}$ & 3 & 3 \\
\hline $\mathrm{E}$ & 6 & 4 \\
\hline Total & 13 & 10 \\
\hline
\end{tabular}

Table 5 Neurological status on admission related to the injured spinal segment

\begin{tabular}{lccc}
\hline $\begin{array}{l}\text { Neurological } \\
\text { Status } \\
\text { (by Frankel) }\end{array}$ & Cervical & $\begin{array}{c}\text { Spinal canal injured } \\
\text { Thoracic/ } \\
\text { Lumbar }\end{array}$ & Total \\
\hline A & 7 & 5 & 12 \\
D + E & 11 & 15 & 26 \\
Total & 18 & 20 & 38 \\
\hline
\end{tabular}

Note: patients with a neurological status of $\mathrm{D}$ and $\mathrm{E}$ have an almost complete, or complete normal function and hence are discussed as one group

Table 6 The immediate neurological outcome (Frankel) of high and low energy injuries

\begin{tabular}{lrcc}
\hline $\begin{array}{l}\text { Type of } \\
\text { Injury }\end{array}$ & A & $\begin{array}{c}\text { Neurological status } \\
D+E\end{array}$ & Total \\
\hline High energy & 6 & 15 & 21 \\
Low energy & 6 & 11 & 17 \\
Total & 12 & 26 & 38 \\
\hline
\end{tabular}

Note: patients with a neurological status of D and E have an almost complete, or complete normal function and hence are discussed as one group that justified inclusion in category ' $A$ ' of Frankel's criteria. This observation suggests that acute radiological postraumatic spinal stenosis does not appear to have a positive clinical cause - effect relationship with loss of neural function, as has already been shown in other studies. ${ }^{12-20}$ This is also supported by the evidence of a non-significant correlation between radiological spinal canal narrowing and the appearance of neurological deficits. This finding is however of limited significance for definite conclusions because it is supported by only one third of the patients in the original study group. However, we think that this observation is of considerable importance showing a significant trend, and may contribute to the controversial issue of the proper therapeutic approach to these patients. $9,11,21,23$

Our study clearly shows that CT imaging alone of the neural canal, providing evidence of bony fragments encroaching on its anatomical diameter, is not siver qua - non with the development of neurological deficit. Some reports suggest that bone spicules in the spinal canal are resorbed with time, ${ }^{11,25}$ while other authors show that the development of irreversible damage to the gray matter of the spinal cord appears to be caused by a cascade of cellular reactions initiated by intraneural hemorrhages which trigger an enzymatic cellular destruction process by local free radicals and lipid peroxidation. ${ }^{22,26-28}$ Therefore, on the basis of our findings we propose that neurological damage will occur only if a sufficient primary impact to the spinal cord has initiated such a destructive cellular process, otherwise there will be no permanent neurological damage. Mechanical damage to the spinal cord by bone encroaching upon the spinal canal is at best very rare, and for all practical purposes will not occur. Furthermore, since no differences in the incidence of neurological deficit and spinal canal narrowing could be found when comparing high energy to low energy injuries, it would appear that it is the local concentration of emitted energy at the point of impact, it's magnitude and direction which determine the development of neurological deficit, unrelated to the degree of spinal stenosis.

The demonstrated significant correlation between the development of immediate postraumatic neurological deficit and neurological status at follow up supports our hypothesis, that the initial impact to the spinal cord determines the future neurological outcome regardless of the spinal segment injured.

In five patients there was a significant functional improvement from Frankel grade ' $A$ ' to ' $D$ '. The neurological improvement occurred in these patients after 4 to 75 days. It may be assumed that in all of these patients, the neural damage had proceeded beyond the cord tissue edema phase. ${ }^{29,30}$ Our explanation for this phenomenon is that these five patients probably had incomplete neurological lesions, which were overlooked on admission.

We suggest that patients with vertebral fractures and radiological evidence of spinal canal compromise 
by bone spicules, who are neurologically intact and therefore treated by conservative means, are not likely to develop functional deterioration.

These findings, which are in keeping with recently published data, ${ }^{19,20,27}$ show that radiological evidence of post traumatic spinal canal narrowing is not necessarily associated with the development of a neurological deficit. Hence the radiological picture of acute post traumatic spinal canal narrowing associated with vertebral fractures appears to be of limited clinical significance.

\section{References}

1 Janssen L, Hansebout RR. Pathogenesis of spinal cord injury and newer treatments - A review. Spine 1989; 14: 23-32.

2 Iisuka $\mathrm{H}$ et al. Evaluation of tissue damage in compressive spinal cord injury in rats. $J$ Neurosurg 1987; 66: 595-603.

3 Hardcastle P, Bedbrook G, Curtis K. Long-term results of conservative and operative management in complete paraplegics with spinal cord injuries between $\mathrm{T} 10$ and L2 with respect to function. Clin Orthop 1987; 224: $88-96$

4 Donovan WH et al. The neurological and skeletal outcome in patients with closed cervical spinal cord injury. J Neurosurg 1987; 66: $690-694$

5 Marshall LF et al. Deterioration following spinal cord injury - A multicenter study. J Neurosurg 1987; 66: 400-404.

6 Maynard FM et al. Neurological prognosis after traumatic quadriplegia - Three years experience of California Regional Spinal Cord Injury Care System. J Neurosurg 1979; 50: 611 - 616

7 Weinstein JN, Collato P, Lehman TR. Thoracolumbar 'burst' fractures treated conservatively - A long term follow up. Spine 1988; 13: $33-38$.

8 Davies WE, Morris JN, Hill V. An analysis of conservative (non surgical) management of thoracolumbar fractures and fracture dislocations with neural damage. JBJS 1980; 62A: 1324-1328.

9 Comarr AE, Kaufman AA. A survey of the neurological results of 858 spinal cord injuries - A comparison of patients treated with and without laminectomy. J Neurosurg 1956; 13: 95-106.

10 Chan DP, Seng NK, Kaan KT. Nonoperative treatment in burst fractures of the lumbar spine (L2-L5) without neurologic deficits. Spine 1993; 18: $320-325$.

11 Munford $\mathbf{J}$ et al. Thoracolumbar burst fractures, the clinical efficacy and outcome of non operative management. Spine 1993; 18: $955-970$
12 Eismond FJ et al. Cervical sagittal spinal canal size in spine injury. Spine 1983; 9: 663-666.

13 McAfee PC et al. The value of computed tomography in thoracolumbar fractures. JBJS 1983; 65A: $461-473$.

14 Trafton PG, Boyd CA. Computed tomography of thoracolumbar spine injuries. J Trauma 1984; 24: $566-575$.

15 Krompinger WJ et al. Conservative treatment of fractures of the thoracic and lumbar spine. Orthop Clin North Am 1986; 12: 161 170 .

16 Weisz GM. Post - traumatic spinal stenosis. Arch Orthop Trauma Surg 1986; 106: $57-60$.

17 Hashimoto T, Kaneda K, Abum K. Relationship between traumatic spinal canal stenosis and neurologic deficits in thoracolumbar burst fractures. Spine 1988; 13: $1268-1272$.

18 Herndon WA, Gollowag D. Neurologic return versus cross sectional canal area in incomplete thoracolumbar spinal cord injures. J Trauma 1988; 28: 680-683.

19 Keene JS et al. Significance of acute post - traumatic bony encroachment of the neural canal. Spine 1989; 14: 799-802.

20 Fontijne WPJ et al. CT scan prediction of neurological deficit in thoracolumbar burst fractures. JBJS 1992; 74B: $683-685$.

21 Jacobs RR, Asher MA, Smider KK. Thoracolumbar spinal injuries - a comparative study of recumbant and operative treatment in 100 patients. Spine 1980; 5: $463-477$.

22 Collins WF, Piepmecer J, Ogle E. The spinal cord injury problem - a review. Cent Nerv Syst Trauma 1986; 3: 317-331.

23 Doerr TE et al. Spinal canal decompression in traumatic thoracolumbar burst fractures: posterior distraction rods versus transpedicular screw fixation. J Orthop Trauma 1991; 5: $403-$ 411.

24 Frankel HL et al. The value of postural reduction in the initial management of closed injuries of the spine with paraplegia and tetraplegia. Paraplegia; 7: 1969; 179-192.

25 Cantor JB et al. Nonoperative management of stable thoracolumbar burst fractures with early ambulation and bracing. Spine 1993; 18: $971-976$.

26 Bedbrook GM. Pathological principles in the management of spinal cord trauma. Paraplegia 1966; 4: $43-56$.

27 Flanders AE et al. Acute cervical spine trauma - Correlation of MR imaging findings with degree of neurological deficit. Radiology 1990; 177: 25-33.

28 Kakulas BA. Pathology of spinal injuries. Cent Nerv Syst Trauma 1989; 1: $117-126$.

29 Benson DR, Keenen TL. Evaluation and treatment of trauma to the vertebral column. Instr Course Lect 1990; 39P: 577-589.

30 Stauffer ES. Diagnosis and prognosis of acute cervical spinal cord injury. Clin Orthop 1975; 112: 9-15. 